\begin{tabular}{l} 
SCIENCE \& TECHNOLOGY \\
Journal homepage: http://www.pertanika.upm.edu.my/ \\
\hline PERTANIKA
\end{tabular}

\title{
Octave Band Technique for Noise Measurement at the Source, Path, and Receiver of Gas Turbines in Oil and Gas Facilities
}

\author{
Akmal Haziq Mohd Yunos* and Nor Azali Azmir \\ Faculty of Mechanical and Manufacturing Engineering, Universiti Tun Hussein Onn Malaysia, Batu Pahat, \\ 86400, Johor Malaysia
}

\begin{abstract}
Noise measurement is essential for industrial usage. However, further attention to preventing noise pollution is needed, especially when working with equipment generating a high noise level, such as gas turbines. This study aims to determine the best way to perform noise measurement and analyze the octave band frequency generated by noise pollution caused by gas turbine equipment. Data from site measurements show that the gas turbines produce more than $85 \mathrm{~dB}$ of noise with a Z-weighted measurement. A noise measuring investigation was conducted to obtain the data for the $1 / 3$ octave band. A frequency-domain was used to comprehend the properties of the noise measurement frequency band. The frequency band was classified into three different zones called low, medium, and high frequency, which is useful in noise measurement analysis to identify a viable solution to reduce the noise. Onsite sampling was performed at the source, path, and receiver of three separate gas turbine locations within oil and gas operations. The 1/3 octave band data collection results at the sound source, path, and receiver demonstrate the noise level distribution at the perimeter of gas turbine installations in the low and medium frequency ranges. Most of the high noise frequency range is between $250 \mathrm{~Hz}$ and $2 \mathrm{kHz}$ for source, path, and receiver. All acquired values are compared to the Department of Safety and Health (Occupational Safety and Health (Noise Exposure) Regulations 2019 in Malaysia. As a result, oil and gas

ARTICLE INFO

Article history:

Received: 18 August 2021

Accepted: 1 November 2021 service operators can monitor and take countermeasures to limit noise exposure at oil and gas facilities.
\end{abstract}

Published: 10 January 2022

DOI: https://doi.org/10.47836/pjst.30.1.39

E-mail addresses:

akmalhaziqmy@gmail.com (Akmal Haziq Mohd Yunos)

azali@uthm.edu.my (Nor Azali Azmir)

*Corresponding author
Keywords: Control measure, gas turbines, noise measurement, Octave band, oil and gas facilities 


\section{INTRODUCTION}

A gas turbine is a turbomachinery piece used to generate electricity for industry. In today's world economy, the gas turbine is essential to power up remote areas, such as oil and gas facilities. It is widely used on the platform to generate power for multiple types of equipment. Since it is vital equipment for the oil and gas industry, it is now looking for a highly efficient gas turbine unit. This equipment will be the only option to generate electricity onboard oil and gas facilities, such as offshore platforms. Turbomachinery equipment is referred to as rotating equipment that uses multiple moving components and creates the power to reach its target performance. However, these components produce excessive noise when the gas turbine operates. It could also be considered a noticeable occupational health issue as it affects the workers' hearing health when carrying out jobs near the gas turbines. A previous study shows that Malaysian workers are affected by noise-induced hearing loss (NIHL), and it was the highest occupational health issue in 2014 (Sam et al., 2017).

Noise is a type of occupational hazard, and the industry should set a target to reduce noise to an acceptable level and help conserve workers' hearing health. This action requires the implementation of any countermeasure that could reduce the volume of noise generated or reduce the noise path through the air and its transmission or through the person exposed to the noise path itself. The countermeasures include engineering modification of equipment, the working area operations, and the room layout itself. The best approach for noise control in the workplace is to reduce the exposure or eliminate noise source generation, either by direct action on the source or by its confinement.

Noise from the engine with a turbofan is produced by a few different parts of the gas turbine and the airflow that generates turbulence. Each noise component produced by the different parts of the engine impacts the overall generated noise depending on the type of turbofan (El-Badawy \& El-Arna'outy, 2007). Engine noise is caused by all engine parts, such as compressors, rotors, stators, combustors, turbine blades, and exhaust. However, the loudest noise is generated by the air intake and the exhaust (Cumpsty \& Marble, 1977). Since the two modules generate the most noise, noise reduction techniques are primarily applied to these modules. A section of gas turbines that is commonly used in the industry is shown in Figure 1.

Noise can cover a broad range of situations, such as excessive vibrations in the structure of mechanical equipment or equipment component failures during operation. The American Academy of Ophthalmology and Otolaryngology has established a sound pressure level that should not exceed $85 \mathrm{~dB}(\mathrm{~A})$ in low and medium frequency for more than 5 hours (Tiede, 1969). Furthermore, in the Occupational Safety and Health (Noise Exposure) Regulation 2019, Regulation 6(2) states that where it appears to an employer that any of his employees are exposed to an excessive noise exceeding the noise exposure limit of daily noise exposure 


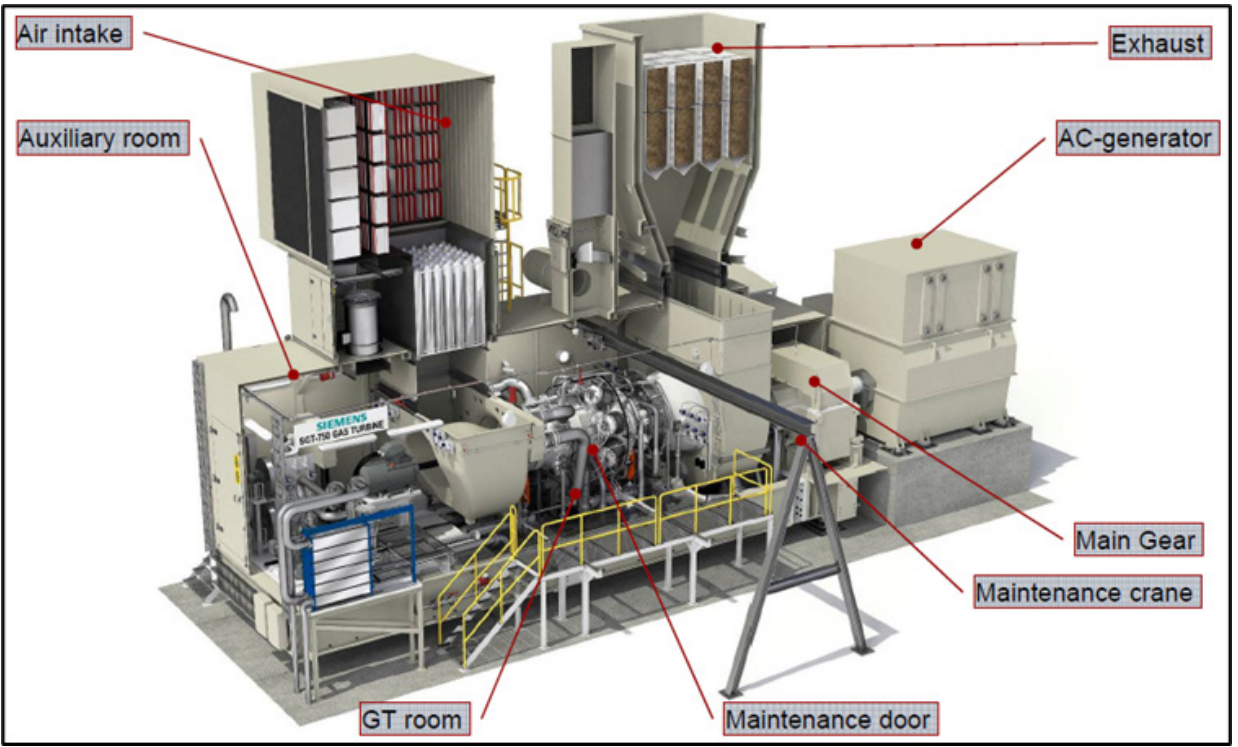

Figure 1. A section of gas turbines (Hellberg et al., 2012)

level of $85 \mathrm{~dB}(\mathrm{~A})$, the employer shall take a countermeasure to reduce the excessive noise (DOSH, 2019). Therefore, it is essential to reduce such excessive noise by carrying out action plans, such as noise measurement at oil and gas facilities and equipment to suppress or attenuate the noise level below $85 \mathrm{~dB}(\mathrm{~A})$.

Noise emission can be a problem in a gas turbine as it can tell the equipment's current condition. It also contributes to occupational health hazards where excessive noise can be fatal to human hearing ability. Therefore, the quiet operation of gas turbine packages has become primary importance in every turbine installation. The degree of noise attenuation required, if any, depends on the location of the installation and the noise environment in which it will be operating (McAuliffe et al., 1963). The outcome of this study could provide initial data for future researchers on how to improve the reliability of gas turbine equipment in the future. It may assist the industry in getting the idea to improve noise control programs at the workplace, and it would be advantageous to choose the most practical principle to reduce noise risk. Furthermore, the market for noise control products in Malaysia can be considered small since the industry is still looking for low-cost ways to control noise. The noise control product market could grow by studying and selecting the most feasible solutions based on noise engineering control techniques.

\section{METHODOLOGY}

This study primarily covers noisy sound source, path and receiver survey, and octave band measurement as a sound frequency parameter that will be done prior to analyzing 
the frequency band. In addition, this methodology covers the technique used for octave band measurement and details on the selected gas turbines. Generally, three methods were employed to conduct the study: pre-values review, on-site data collection, and post-noise analysis work. The flow chart in Figure 2 portrays the main steps of conducting this study, starting from document review until discussion on how to measure the effectiveness of the noise control option on noisy equipment and areas based on octave band frequency analysis.

A pre-job process is essential to understand how the equipment operates as it helps gather the information required for further evaluation. The operation history of the equipment also increases the chances of developing a strategy to solve noise issues on the equipment. Technical information is gathered, including equipment data sheets, factory acceptance test (FAT) reports, existing noise exposure monitoring (NEM) reports, mechanical drawings, and piping and instrument diagrams (P\&ID) before the on-site job.

The on-site job consists of preparing data collection and measurement jobs on site. It will be a process where noise surveying is done using octave band measurement, and the area or location producing noise emission is identified. The octave band data is collected on all points, including the source, noise path, and receiver. Once the octave band data has been measured on-site, it will be analyzed with a theoretical study and calculation. The noise control analysis for the gas turbines plays with noise reduction coefficients to select a suitable material to absorb the noise with a calculation of sound transmission loss.

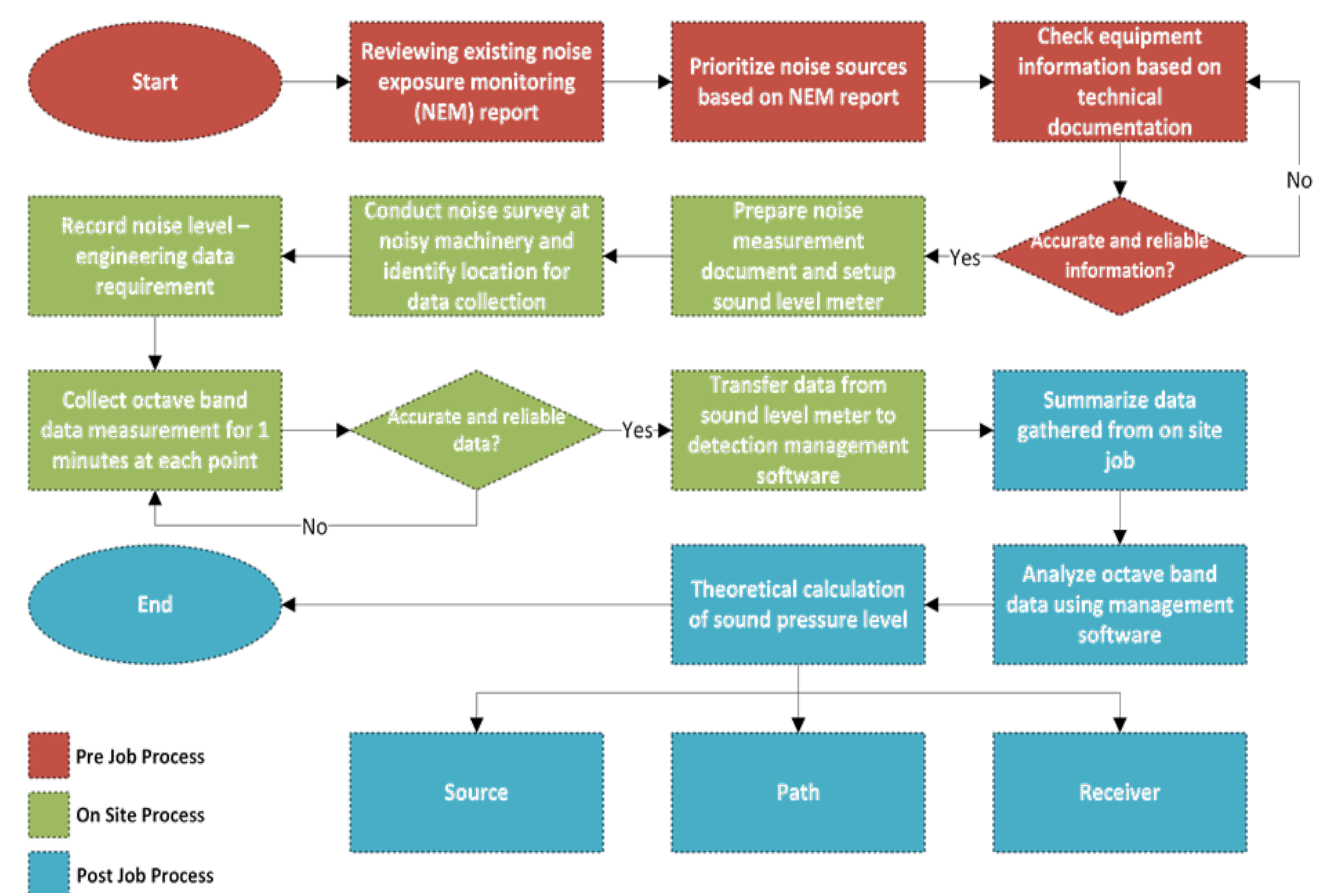

Figure 2. Process flowchart 


\section{Noise Measurement}

Noise measurement is the only way to gather the data to select a possible way to reduce the sound intensity of gas turbines. Sound is known as vibration energy that transmits through an airwave, while noise is unwanted sound (CCOHS, 2019). The noise is measured in three categories: source, path, and receiver. Anything that emits noise without any engineering control measures will be considered a sound source. However, if any existing engineering control measure is found, it is viewed as a sound path. The sound receiver defines noise emission at a worker's location, such as inside the control room or enclosure where the worker takes a parameter reading or performs an inspection job.

The noise measurement is located as close as (less than 1-meter perimeter) at the gas turbine for each source, path, and receiver location. In addition, the noise inside and outside the gas turbine generator room or enclosure is taken to determine the existing equipment enclosure effectiveness. For this study, one SoundPro SP SE-1-1/3 sound level meter was used with an AC-300 acoustic calibrator to collect the readings. Before on-site noise data collection, the sound level meter is set to the maximum of $140 \mathrm{~dB}$ magnitude of noise level with a selection of $1 / 3$ octave bandwidth. The exchange rate used is $3 \mathrm{~dB}$, and $\mathrm{Z}$-weighting and the fast response are chosen. A Z-weighting was used to get a trend for low-frequency noise generation, and 1/3 octave band data collection aimed to determine the dominant frequency band that emits a high noise level (Peters, 2013). In order to achieve more accurate data, the time taken to get a reading on each point was set at 1 minute.

The range of interest of frequency is between $12.5 \mathrm{~Hz}$ and $20 \mathrm{kHz}$, according to the human hearing range. Fundamentally, the noise frequency band is separated into three categories, which are low frequency $(12.5 \mathrm{~Hz}$ to $200 \mathrm{~Hz}$ ), medium frequency (200 Hz to 2 $\mathrm{kHz}$ ), and high frequency ( $2 \mathrm{kHz}$ to $20 \mathrm{kHz}$ ). The measurement of $\mathrm{dB}(\mathrm{Z})$ does not filter all noise frequency bandwidths. The standard used to convert $\mathrm{dB}(\mathrm{Z})$ to $\mathrm{dB}(\mathrm{A})$ measurement is BS 61672-1:2003. The $\mathrm{dB}(\mathrm{A})$ level is calculated using the standard magnitude level reduction for each frequency bandwidth. The data gathered from the $1 / 3$ octave band is used as generic data to select the $1 / 1$ octave band, including $63 \mathrm{~Hz}, 125 \mathrm{~Hz}, 250 \mathrm{~Hz}, 500$ $\mathrm{Hz}, 1000 \mathrm{~Hz}, 2000 \mathrm{~Hz}, 4000 \mathrm{~Hz}$, and $8000 \mathrm{~Hz}$. These frequencies are used to calculate sound absorption and transmission loss.

For this study, three gas turbines were chosen and nominated Gas Turbine A, Gas Turbine B, and Gas Turbine C. Gas Turbine A is located inside a gas turbine room, while Gas Turbine B and Gas Turbine $\mathrm{C}$ are in an open area. The schematic diagram for all three turbines and the data collected is shown in Figures 3(a) to 3(c).

Since Gas Turbine A enclosure is located inside a gas turbine room, the noise measurement at the source will be taken inside the enclosure, while noise at the path will be taken inside the gas turbine room after the enclosure door is closed. The noise measurement at the receiver will be taken outside the gas turbine room. 


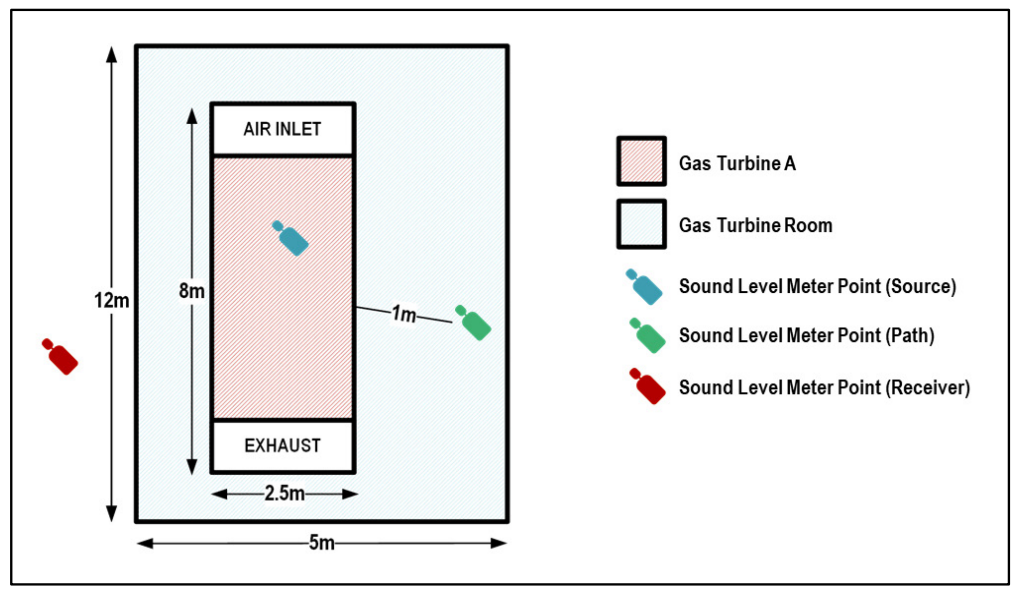

(a)

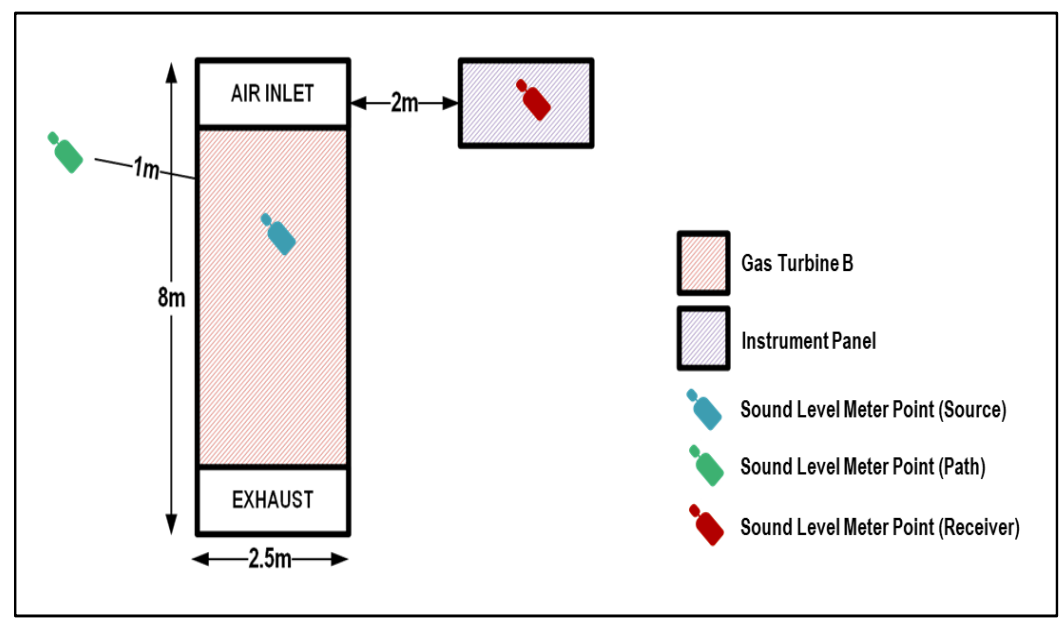

(b)

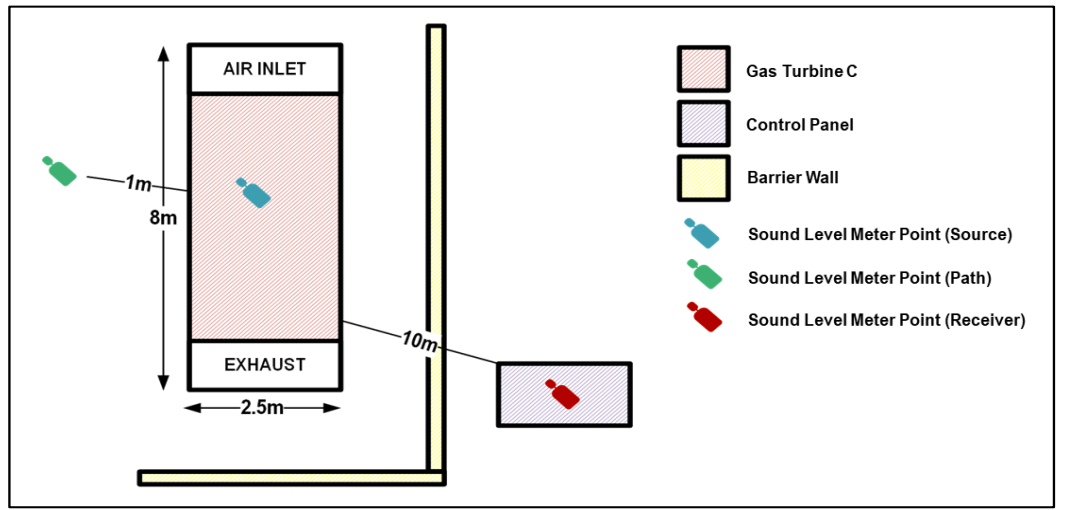

(c)

Figure 3. (a) Diagram of measurement point for Gas Turbine A; (b) Diagram of measurement point for Gas Turbine B; (c) Diagram of measurement point for Gas Turbine C 
Gas Turbine B is in an open area where the only noise control measure will be the gas turbine enclosure. Therefore, for Gas Turbine B, the noise source reading will be taken inside the enclosure, and noise along the path will be taken outside the enclosure with a closed door.

A noise reading will be taken at the instrument panel point located 2 meters from the gas turbine enclosure.

For Gas Turbine C, it was in an open area, and a barrier wall was used to split the area of the gas turbine and control room. The noise source reading will be taken inside the enclosure, and noise along the path will be taken outside the enclosure with a closed enclosure door. The receiver data was collected inside the control room, located 10 meters from the gas turbine.

\section{Noise Control Strategies}

Once the data has been collected, the analysis is done based on planned noise measurement strategies. Referring to the principle, acoustical properties continuously reflect, absorb, or transmit the sound that strikes on the component as all materials have some soundabsorbing properties. If a sound wave hits any surface, the energy is divided into several paths. Some energy is reflected, some are absorbed, and others are transmitted through the material. However, the portion for each path of sound energy is not always the same for all conditions. It always depends on the acoustic performance of the material used. Figure 4 shows the phenomenon of sound interaction with acoustic material.

The incident sound energy that is

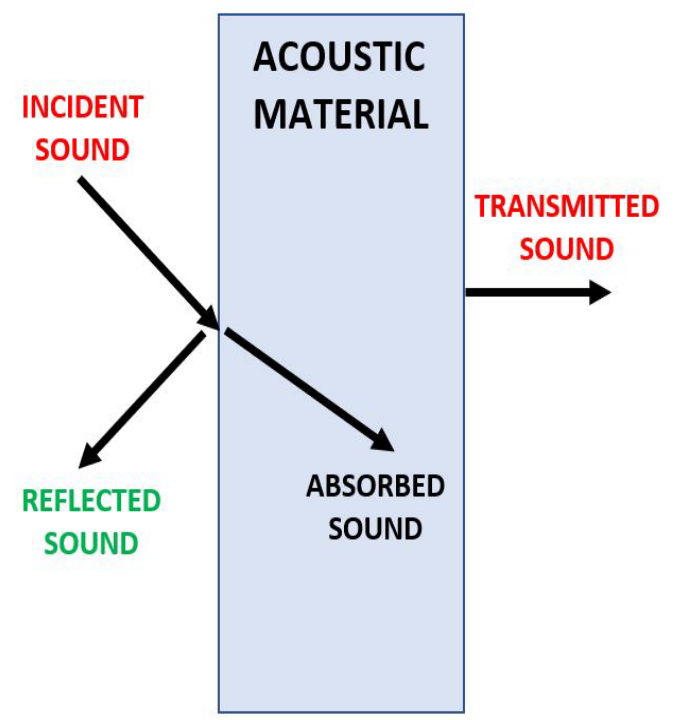

Figure 4. Interaction of sound wave on material not absorbed by material needs to reflect and be transmitted and dissipated. For acoustical material, acoustic performance can be obtained by three characterizations, namely: Sound absorption coefficient $(\alpha)$, noise reduction coefficient (NRC), and sound transmission loss (STL). The sound absorption coefficient $(\alpha)$ is a prominent feature in defining the performance of any material used for a specific purpose. As shown in Equation 1, the sound absorption coefficient is determined as the ratio of sound energy absorbed to the incident sound energy striking a material. 


$$
\alpha=\frac{\left(\boldsymbol{I}_{\boldsymbol{a}}+\boldsymbol{I}_{\boldsymbol{t}}\right)}{\boldsymbol{I}_{\boldsymbol{i}}}
$$

Where:

$\boldsymbol{\alpha}=$ sound absorption coefficient

$\boldsymbol{I}_{\boldsymbol{a}}=$ Sound absorbed $\left(\mathrm{W} / \mathrm{m}^{2}\right)$

$\boldsymbol{I}_{\boldsymbol{i}}=$ Incident sound energy $\left(\mathrm{W} / \mathrm{m}^{2}\right)$

$\boldsymbol{I}_{\boldsymbol{t}}=$ Sound transmission $\left(\mathrm{W} / \mathrm{m}^{2}\right)$

The sound absorption coefficient is a unitless quantity where the value lies between zero and 1.0. When a material has zero sound absorption value, there is no sound absorption as incident sound energy is being reflected or transmitted. On the other hand, when a material has a value of 1.0, it shows that it absorbs all incident sound energy.

\section{Noise Reduction Coefficient}

The calculation of the Noise Reduction Coefficient (NRC) is one of the parameters used to define material acoustic performance, particularly for sound absorber materials. NRC is the average measured sound absorption coefficient value at several frequencies and provides a more straightforward NRC form. The value is used as an index of the sound-absorbing efficiency of the material. Based on ASTM C423-17 (2017), the Standard Method of Test for Sound Absorption of Acoustic Materials in Reverberant Rooms, NRC's value is calculated as shown in Equation 2 by summing up low, medium, and high-frequency NRC values and dividing them by the number of counts.

$$
N R C=\frac{\alpha_{250}+\alpha_{500}+\alpha_{1000}+\alpha_{2000}}{4}
$$

\section{Sound Transmission Loss}

Apart from the Noise Reduction Coefficient, another calculation is the Sound Transmission Loss (STL). A transmitted sound wave is commonly used to find out the sound insulation ability. Sound transmission loss is the value that represents the ratio of sound energy transmitted through treatment to the amount of sound energy incident on the source side of the material. This value is measured in decibels $(\mathrm{dB})$, where a material isolates the sound in a specific octave band. The test follows ASTM E90-09 (2009), the Standard Recommendation Practice for Laboratory Measurement of Airborne Sound Transmission Loss of Building Partitions. Similar to sound absorption, the transmission loss is defined by the following Equation 3: 


$$
S T L=10 \log \left(\frac{W_{i}}{W_{t}}\right)
$$

Where:

$\boldsymbol{W}_{\boldsymbol{i}}=$ Incident sound power

$\boldsymbol{W}_{\boldsymbol{t}}=$ Transmitted sound power

\section{RESULTS AND DISCUSSION}

The results from three different gas turbines located at three different facilities denoted as Gas Turbine A, Gas Turbine B, and Gas Turbine C are presented. The summary from the data collection is discussed with a possible noise control recommendation for each gas turbine unit.

\section{Gas Turbine A}

Octave band frequency data for all sampling points at Gas Turbine A is shown in Table 1 for noise source, path, and receiver location. The highest noise source level is detected in the middle section of the gas turbine equipment, with an average sound radiation level of $100.9 \mathrm{~dB}(\mathrm{Z})$ due to gas turbine operation. The frequency of interest contributing to noise is between $50 \mathrm{~Hz}$ and $20 \mathrm{kHz}$. The highest noise path level location is the generator rotor bearing, with an average sound radiation level of $104.6 \mathrm{~dB}(\mathrm{Z})$. The frequency of interest contributing to noise is between $80 \mathrm{~Hz}$ and $5 \mathrm{kHz}$. The highest sound level at the receiver is detected outside the generator room, where the gas turbine exhaust silencer duct and stack are located, with a sound level of $100.6 \mathrm{~dB}(\mathrm{Z})$. The frequency of interest contributing to noise is between $63 \mathrm{~Hz}$ and $250 \mathrm{~Hz}$.

\section{Table 1}

Gas turbine A octave band data

\begin{tabular}{lccccccccccc}
\hline & \multicolumn{8}{c}{ Octave Band Frequency } \\
Location & $\mathbf{3 1 . 5}$ & $\mathbf{6 3}$ & $\mathbf{1 2 5}$ & $\mathbf{2 5 0}$ & $\mathbf{5 0 0}$ & $\mathbf{1 0 0 0}$ & $\mathbf{2 0 0 0}$ & $\mathbf{4 0 0 0}$ & $\mathbf{8 0 0 0}$ & $\begin{array}{c}\text { Noise } \\
\text { Level } \\
\mathbf{d B}(\mathbf{Z})\end{array}$ \\
\hline Source & 79 & 86.9 & 85.3 & 88.3 & 88.1 & 95.9 & 87.7 & 92.7 & 95.6 & 100.9 \\
Path & 81.7 & 83.9 & 92.9 & 101.2 & 97.8 & 96.3 & 93.9 & 88.8 & 81.3 & 104.6 \\
Receiver & 80.8 & 99.9 & 90.1 & 87.8 & 75.3 & 73.5 & 63.6 & 59.8 & 48.1 & 100.6 \\
\hline
\end{tabular}




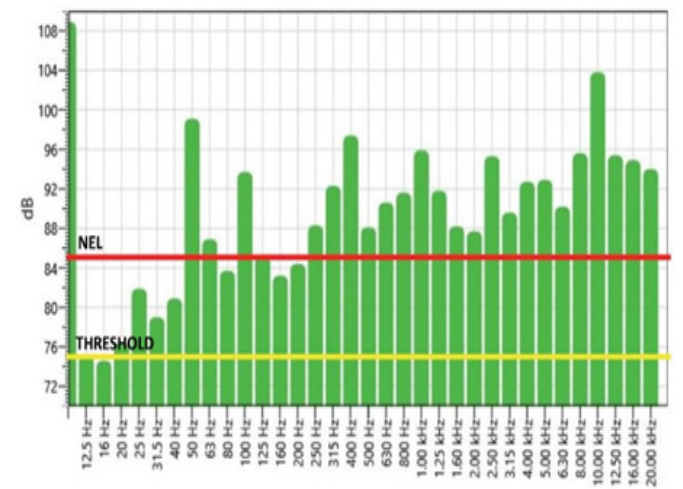

(a)

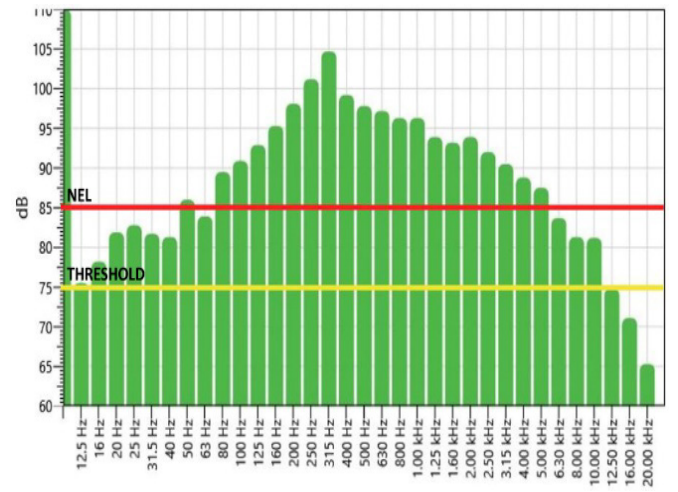

(b)

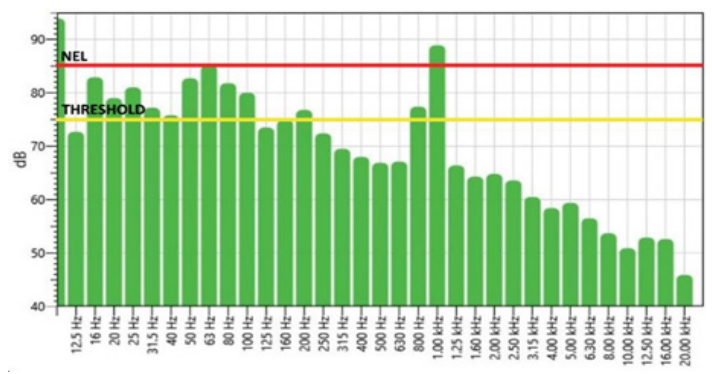

(c)

Figure 5. (a) Gas turbine A source reading; (b) Gas turbine A path reading; (c) Gas turbine A receiver reading

Based on the measurement data shown in Figures 5(a) to 5(c) for the noise source, path, and receiver, the excessive noise localized at the generator rotor rotation area is located at the guarding air inlet. It indicates a very high noise level of $110 \mathrm{~dB}(\mathrm{Z})$. The red line indicates the noise level of $85 \mathrm{~dB}$ (high), or what can be called the Noise Exposure Limit (NEL), while the yellow line indicates $75 \mathrm{~dB}$ (low) of the noise level or noise threshold. The reason to set up the high and low limits is to visualize the distribution of noise levels at each respective frequency of interest. $75 \mathrm{~dB}$ was chosen as the low noise level, as any reading below $75 \mathrm{~dB}$ will be ignored. The reason is that the numerical difference between the two noise values is zero, and it will not contribute to the whole noise data (CCOHS, 2019). The sound source is measured during the turbine enclosure door is opened, while the sound path is measured at the perimeter of the gas turbine generator machine during the enclosure door is closed. The noise level measured closely at the generator rotor bearing open area (path) exceeds $85 \mathrm{~dB}(\mathrm{Z})$ in the frequency band from $80 \mathrm{~Hz}$ to $5 \mathrm{kHz}$, generated by aerodynamic air inlet flow and mechanical centrifugal force. An average attenuation rate calculated from the sound source and sound path difference is around $\pm 8 \mathrm{~dB}$. Therefore, the existing enclosure cannot reduce the noise below $85 \mathrm{~dB}(\mathrm{~A})$ in the Gas Turbine A area. 


\section{Gas Turbine B}

As with Gas Turbine A, the process for data collection at Gas Turbine B will acquire the octave band data at the source, path, and receiver. The measurement data is shown in Table 2 . The highest noise source level is located inside the gas turbine generator enclosure with an average sound radiation level of $104.0 \mathrm{~dB}(\mathrm{Z})$. Besides that, the highest noise level along the path outside the gas turbine generator is measured at an average sound pressure level of $96.8 \mathrm{~dB}(\mathrm{Z})$. It indicates that the noise energy emission is initiated at the gas turbine exhaust vent. The high-frequency aerodynamic noise radiates from the 90 -degree exhaust vent design without lagging due to turbulence gas effects. On the receiver side, the noise level is recorded at $90.6 \mathrm{~dB}(\mathrm{Z})$.

Table 2

Gas turbine B octave band data

\begin{tabular}{lcccccccccccc}
\hline & \multicolumn{8}{c}{ Octave Band Frequency } \\
Location & $\mathbf{3 1 . 5}$ & $\mathbf{6 3}$ & $\mathbf{1 2 5}$ & $\mathbf{2 5 0}$ & $\mathbf{5 0 0}$ & $\mathbf{1 0 0 0}$ & $\mathbf{2 0 0 0}$ & $\mathbf{4 0 0 0}$ & $\mathbf{8 0 0 0}$ & $\begin{array}{c}\text { Noise } \\
\text { Level } \\
\mathbf{d B}(\mathbf{Z})\end{array}$ \\
\hline Source & 81.3 & 88.7 & 100.2 & 97.4 & 95.5 & 92.9 & 92.9 & 88 & 83.4 & 104.0 \\
Path & 71.7 & 82 & 84 & 83 & 83. & 95.6 & 82 & 80.3 & 71.8 & 96.8 \\
Receiver & 68.2 & 73.4 & 87.6 & 81.9 & 77.2 & 84.3 & 73.4 & 75.1 & 66.3 & 90.6 \\
\hline
\end{tabular}

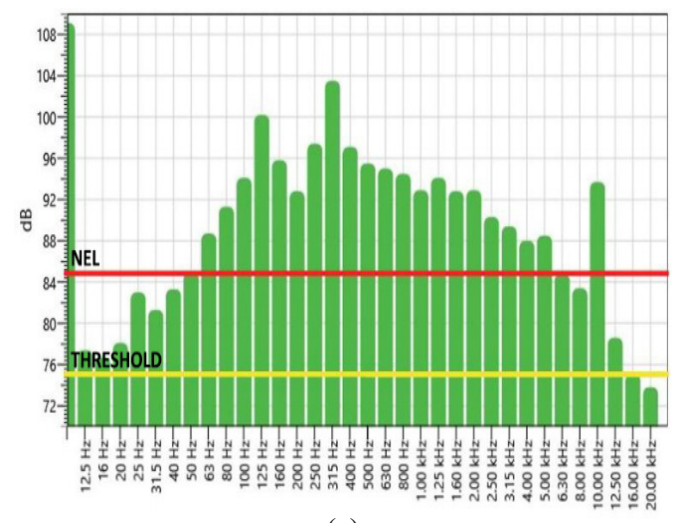

(a)

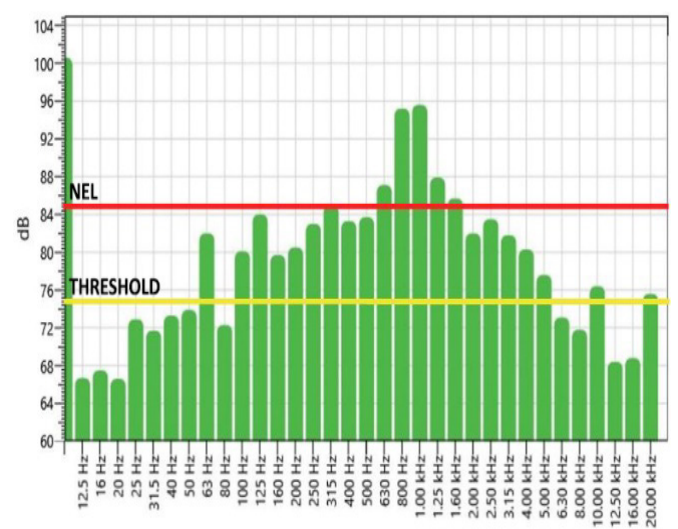

(b) 


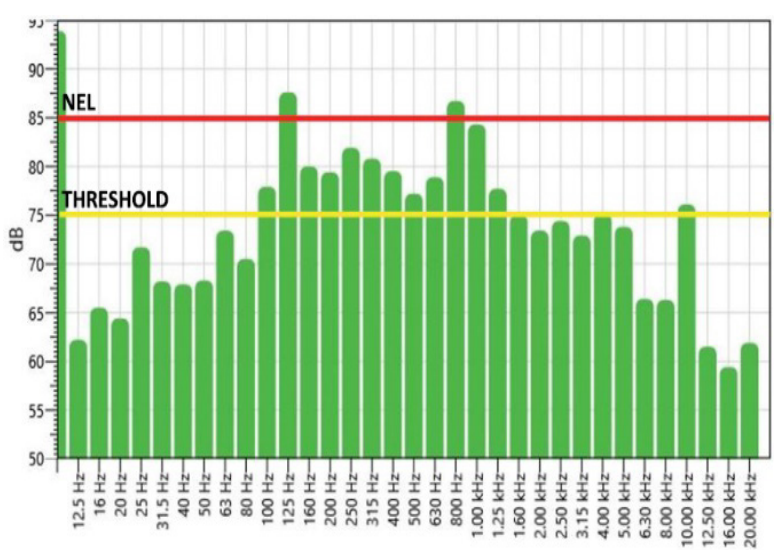

(c)

Figure 6. (a) Gas Turbine B source reading; (b) Gas Turbine B path reading; (c) Gas Turbine B receiver reading

Based on the 1/3 octave band data in Figures 6(a) to 6(c), the sound level at the source shows that the noise level is distributed at low-to high-frequency ranges of $63 \mathrm{~Hz}$ to $10 \mathrm{kHz}$ inside the gas turbine enclosure. Two pure tone frequencies spike a high noise magnitude at $125 \mathrm{~Hz}$ and $315 \mathrm{~Hz}$, reaching more than $100 \mathrm{~dB}(\mathrm{Z})$. It is due to the high rotation of the turbine engine and electrical noise. The equivalent noise emission is recorded between 108 $\mathrm{dB}(\mathrm{Z})$ and $109.6 \mathrm{~dB}(\mathrm{Z})$ at all sampling points. The sampling point at path location shows that the dominant medium frequency of noise bandwidth contributes to accumulating a high level of noise distribution of $90.6 \mathrm{~dB}(\mathrm{Z})$ to $100.6 \mathrm{~dB}(\mathrm{Z})$. The low-frequency noise distribution comes from the top side gas turbine exhaust vent outlet. The right-left and sides of an enclosure show an average noise attenuation of $15 \mathrm{~dB}(\mathrm{Z})$.

\section{Gas Turbine C}

As for the third sample, Gas Turbine C, the octave band frequency data for all sampling points at the gas turbine generator are shown in Table 3 for noise source, path, and receiver location. The highest noise source level is recorded at an average sound radiation level of $103.5 \mathrm{~dB}(\mathrm{Z})$.

Most of the noise frequency band distribution ranges from $12.5 \mathrm{~Hz}$ to $3.15 \mathrm{kHz}$. Meanwhile, for the noise path, the highest noise level is measured at $100.2 \mathrm{~dB}(\mathrm{Z})$ and is dominant at $1 \mathrm{kHz}$ and $1.25 \mathrm{kHz}$ frequency bandwidths. The sound receiver is recorded at $63.9 \mathrm{~dB}(\mathrm{Z})$, indicated below the quiet zone of $80 \mathrm{~dB}(\mathrm{Z})$. 
Table 3

Gas Turbine Coctave band data

\begin{tabular}{lccccccccccc}
\hline & \multicolumn{8}{c}{ Octave Band Frequency } & & $\begin{array}{c}\text { Noise } \\
\text { Level } \\
\text { Location }\end{array}$ \\
& $\mathbf{3 1 . 5}$ & $\mathbf{6 3}$ & $\mathbf{1 2 5}$ & $\mathbf{2 5 0}$ & $\mathbf{5 0 0}$ & $\mathbf{1 0 0 0}$ & $\mathbf{2 0 0 0}$ & $\mathbf{4 0 0 0}$ & $\mathbf{8 0 0 0}$ & $\mathbf{d}(\mathbf{Z})$ \\
\hline Source & 94.9 & 95.9 & 93.5 & 98.6 & 94.3 & 91.9 & 90.8 & 83.6 & 78.4 & 103.5 \\
Path & 86.2 & 79.1 & 81.7 & 85.3 & 94.6 & 97.9 & 84.4 & 77.3 & 82.3 & 100.2 \\
Receiver & 57.4 & 55.5 & 56.2 & 58.7 & 60.6 & 53.4 & 55.5 & 48.8 & 42.4 & 65.9 \\
\hline
\end{tabular}

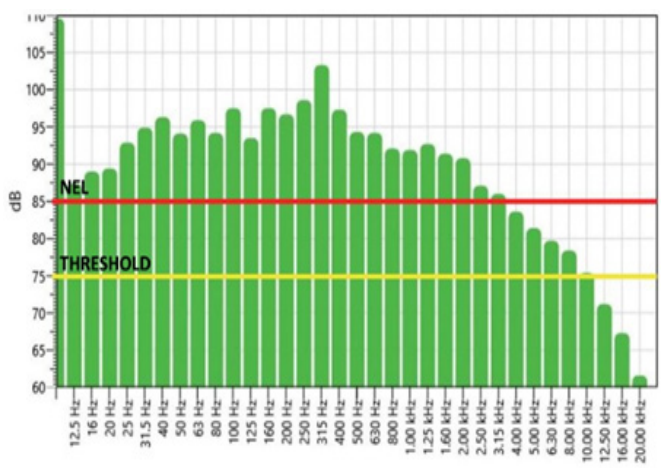

(a)

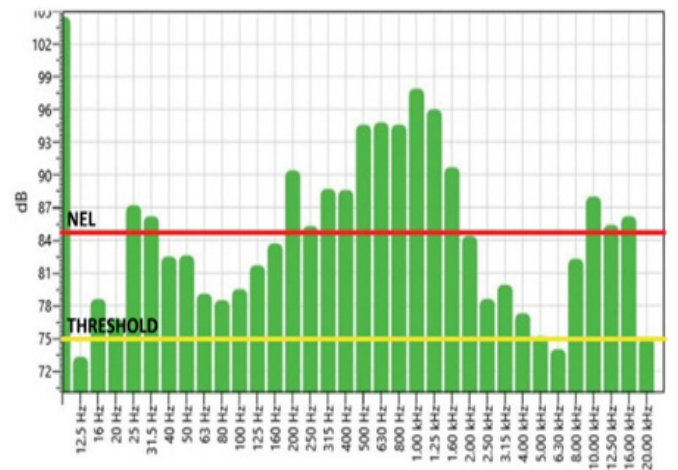

(b)

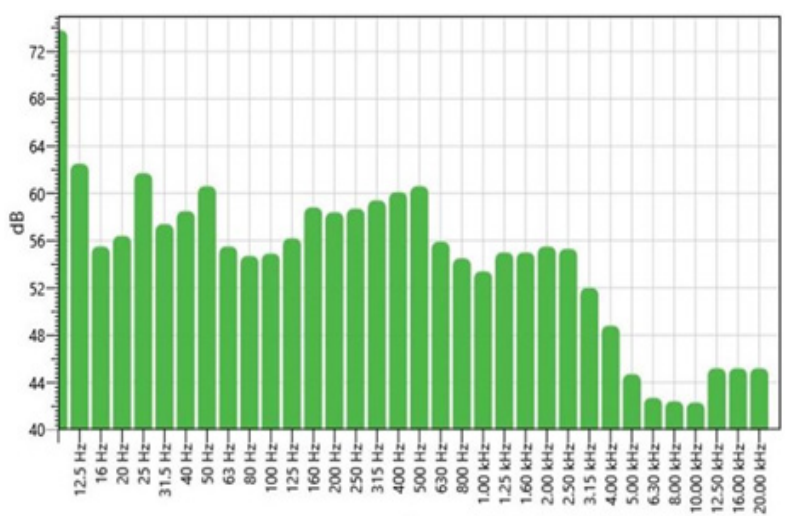

(c)

Figure 7. (a) Gas Turbine C source reading; (b) Gas Turbine C path reading; (c) Gas Turbine C receiver reading

The sound source of the $1 / 3$ octave band results indicates that the noise level distributions are at low, medium, and high frequency ranges inside the gas turbine enclosure, 
as shown in Figures 7(a) to 7(c). Most noise level magnitude at each frequency band excites more than $85 \mathrm{~dB}(\mathrm{Z})$. It is due to the rotation speed of the turbine engine and electrical noise. The sampling point at path location shows that the dominant medium frequency of noise bandwidth contributes to the accumulation of high noise distributions between 90 $\mathrm{dB}(\mathrm{Z})$ and $98 \mathrm{~dB}(\mathrm{Z})$. The low frequency of noise distribution comes from the topside gas turbine inlet and outlet air vents. However, the dominant $200 \mathrm{~Hz}$ to $1.6 \mathrm{kHz}$ frequency band is found at the connecting duct between gas turbine enclosures and exhaust silencers. The sampling point at the receiver location, the gas turbine control room, shows a result below $80 \mathrm{~dB}(\mathrm{Z})$.

\section{Octave Band Calculation}

A noise reduction calculation is made by calculating the noise reduction coefficient and sound transmission loss for the equipment. In this study, a modular acoustic panel is used as an example. By utilizing an on-site dimension, the area for acoustic treatment is defined in the calculation. The example of the analysis is shown in Figures 8 to 13. For this example, the noise source reading from Gas Turbine A is an input. The distance from the primary source also needs to consider the directivity factor. Two directivities have been chosen by referring to the gas turbine location inside the enclosure base.

\begin{tabular}{|l|c|}
\hline \multicolumn{2}{|c|}{ AREA DIMENSIONS $(\mathrm{ft})$} \\
\hline Length & 30 \\
\hline Width & 8 \\
\hline Height & 7 \\
\hline
\end{tabular}

\begin{tabular}{|l|c|c|c|c|c|c|}
\hline \multicolumn{7}{|c|}{ ACOUSTIC MATERIAL ABSORPTION COEFFICIENT (EXAMPLE) } \\
\hline & \multicolumn{7}{|c|}{ FREQUENCY (Hz) } \\
\cline { 2 - 7 } & $\mathbf{1 2 5}$ & $\mathbf{2 5 0}$ & $\mathbf{5 0 0}$ & $\mathbf{1 0 0 0}$ & $\mathbf{2 0 0 0}$ & $\mathbf{4 0 0 0}$ \\
\hline Floor & 0.71 & 1.09 & 1.03 & 1.05 & 0.98 & 0.89 \\
\hline Ceiling & 0.71 & 1.09 & 1.03 & 1.05 & 0.98 & 0.89 \\
\hline Walls & 0.71 & 1.09 & 1.03 & 1.05 & 0.98 & 0.89 \\
\hline
\end{tabular}

\begin{tabular}{|c|c|c|c|c|c|c|}
\hline \multicolumn{7}{|c|}{ SOUND PRESSURE LEVEL (GAS TURBINE A SOURCE) } \\
\hline FREUENCY (Hz) \\
\hline 125 & 250 & 500 & 1000 & 2000 & 4000 & \\
\hline 85.3 & 88.3 & 88.1 & 95.9 & 87.7 & 92.7 & 99.0 \\
\hline
\end{tabular}

Figure 8. Input data for noise reduction calculation

\begin{tabular}{|l|c|}
\hline \multicolumn{2}{|c|}{$\begin{array}{c}\text { DIRECTIVITY FACTOR } \\
\text { (ft) }\end{array}$} \\
\hline Distance & 1 \\
\hline Directivity & 2 \\
\hline
\end{tabular}

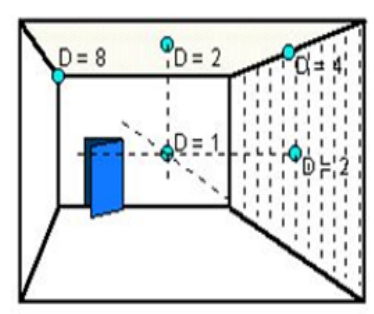


The overall noise pressure level for Gas Turbine A (Source) was calculated using an equivalent continuous sound energy level (Leq) based on the BS 61672 standard. The formula for the equivalent sound level is as follows:

$$
\begin{aligned}
& L_{e q}=10 \log \left(10^{\frac{L 1}{10}}+10^{\frac{L 2}{10}}+10^{\frac{L_{n}}{10}}\right) \\
& =10 \log \left(10^{\frac{85.3}{10}}+10^{\frac{88.3}{10}}+10^{\frac{88.1}{10}}+10^{\frac{95.9}{10}}+10^{\frac{87.7}{10}}\right. \\
& \left.+10^{\frac{92.7}{10}}\right) \\
& =99 \mathrm{dBA}
\end{aligned}
$$

The average absorption coefficient and room constant are calculated using the surface area and treated surface with selected acoustic material absorption values at $125 \mathrm{~Hz}, 250$ $\mathrm{Hz}, 500 \mathrm{~Hz}, 1000 \mathrm{~Hz}, 2000 \mathrm{~Hz}$, and $4000 \mathrm{~Hz}$ frequencies. Absorption can be calculated by dividing the total room sound absorption by the total surface area of the room. The total room sound absorption can be calculated by multiplying the surface area with the absorption coefficient of the actual surface. The frequency of $125 \mathrm{~Hz}$ is used as an example for the whole calculation:

Average Absorption Coefficient $=[$ Total Sound Absorption (Floor) + Total Sound Absorption (Ceiling) + Total Sound Absorption (Wall)] / Total Surface Area in the Room

$=[(240 \times 0.71)+(240 \times 0.71)+(532 \times 0.71)] / 1012$

$=0.71$

The result for the average absorption coefficient for the rest of the frequency is as follows:

\begin{tabular}{|c|c|c|c|c|c|}
\hline \multicolumn{7}{|c|}{ AVERAGE ABSORPTION COEFFICIENT } \\
\hline 125 & 250 & 500 & 1000 & 2000 & 4000 \\
\hline 0.71 & 1.09 & 1.03 & 1.05 & 0.98 & 0.89 \\
\hline
\end{tabular}

Figure 9. Average absorption coefficient result 
Once the result of the average absorption coefficient is obtained, the room constant can be calculated as follows:

Room Constant $=$ Total Room Sound Absorption / (1 - Average Absorption Coefficient $)$

$=(1012 \times 0.71) /(1-0.71)$

$=2477.7$

\begin{tabular}{|c|c|c|c|c|c|}
\hline \multicolumn{7}{|c|}{ ROOM CONSTANT (sqft) } \\
\hline \multicolumn{7}{|c|}{ FREQUENCY (Hz) } \\
\hline 125 & $\mathbf{2 5 0}$ & $\mathbf{5 0 0}$ & $\mathbf{1 0 0 0}$ & $\mathbf{2 0 0 0}$ & $\mathbf{4 0 0 0}$ \\
\hline 2477.7 & -12256.4 & -34745.3 & -21252.0 & 49588.0 & 8188.0 \\
\hline
\end{tabular}

Figure 10. Room constant result

A reduction when using a modular acoustic panel can be seen once a sound pressure level calculation using the directivity factor is done. Based on the Directivity Factor formula,

$$
L_{P}=L_{N}+\log \left(\left(D / / 4 \pi r^{2}\right)+\left(\frac{4}{R}\right)\right)
$$

Where:

$\boldsymbol{L}_{\boldsymbol{p}} \quad=$ Sound Pressure Level (After)

$L_{N} \quad=$ Sound Power Level from source (Before)

D $\quad$ Directivity Factor

$\boldsymbol{r} \quad=$ Distance

$\boldsymbol{R} \quad=$ Room Constant

$=85.3+\log \left(\left(2 / / 4 \pi(1)^{2}\right)+\left(\frac{4}{2477.7}\right)\right)$

$=77.4$

\begin{tabular}{|c|c|c|c|c|c|c|}
\hline \multicolumn{6}{|c|}{ SOUND PRESSURE LEVEL (dB) } & \\
\hline \multicolumn{6}{|c|}{ FREQUENCY (Hz) } & \\
\hline 125 & 250 & 500 & 1000 & 2000 & 4000 & Linear \\
\hline 77.4 & 80.3 & 80.1 & 87.9 & 79.7 & 84.7 & 91.1 \\
\hline
\end{tabular}

Figure 11. Sound pressure level result 
The sound pressure level can be corrected into A-weighted by using the BS 616721:2003 standard, and the outcome can be seen in Figure 12. The overall difference between before ( $99 \mathrm{dBA})$ and after applying a modular acoustic panel at the source of Gas Turbine $\mathrm{A}(90.7 \mathrm{dBA})$ is about $8.3 \mathrm{dBA}$.

\begin{tabular}{|c|c|c|c|c|c|c|}
\hline \multicolumn{6}{|c|}{ A-WEIGHTED SOUND LEVEL (dBA) } & \\
\hline \multicolumn{6}{|c|}{ FREQUENCY (Hz) } & \\
\hline 125 & 250 & 500 & 1000 & 2000 & 4000 & Linear \\
\hline 61.3 & 71.7 & 76.9 & 87.9 & 80.9 & 85.7 & 90.7 \\
\hline
\end{tabular}

Figure 12. A-Weighted corrected sound level

Figure 13 depicts a comparison of the sound pressure levels of three gas turbines. Gas Turbine B and Gas Turbine C, located in an open area, recorded a higher difference in sound pressure level compared to Gas Turbine A, located in a gas turbine room.

\begin{tabular}{|c|c|c|c|}
\hline & \multicolumn{3}{|c|}{ COMPARISON (dBA) } \\
\hline & Before & After & Difference \\
\hline Gas Turbine A & 99.0 & 90.7 & 8.3 \\
\hline Gas Turbine B & 103.8 & 91.1 & 12.7 \\
\hline Gas Turbine C & 101.8 & 89.6 & 12.2 \\
\hline
\end{tabular}

Figure 13. Comparison of noise reduction between three gas turbines

As for the sound transmission loss, the example for the calculation is shown in Figure 14. The same acoustic material is used for sound transmission loss calculation following the noise reduction coefficient analysis. The minimum insertion loss or transmission loss value is used at 125, 250, 500, 1000, 2000, 4000, and $8000 \mathrm{~Hz}$ frequencies. The linear sound pressure level and A-weighted sound pressure level are automatically calculated by deducting the sound pressure level from the source with transmission loss. Correcting the linear sound pressure level with an A-weighting correction value from the BS 61672 standard will give out an A-weighted sound level. The overall sound level reduction of $26.8 \mathrm{~dB}$ is achieved to reduce the noise level for Gas Turbine A. The main important element in selecting proper noise absorption and transmission material is determining the material properties. 


\begin{tabular}{|c|c|c|c|c|c|c|}
\hline \multicolumn{7}{|c|}{ SOUND PRESSURE LEVEL (GAS TURBINE A SOURCE) } \\
\multirow{2}{|c|}{ FREUENCY (Hz) } \\
\hline 125 & 250 & 500 & 1000 & 2000 & 4000 & \\
\hline 85.3 & 88.3 & 88.1 & 95.9 & 87.7 & 92.7 & $99.0 \mathrm{~dB}$ \\
\hline
\end{tabular}

\begin{tabular}{|c|c|c|c|c|c|}
\hline \multicolumn{7}{|c|}{ TRANSMISSION LOSS (example) } \\
\hline 125 & 250 & 500 & 1000 & 2000 & 4000 \\
\hline 16 & 20 & 29 & 38 & 42 & 48 \\
\hline
\end{tabular}

LINEAR SOUND PRESSURE LEVEL

\begin{tabular}{|c|c|c|c|c|c|c|}
\hline \multicolumn{6}{|c|}{ FREQUENCY $(\mathrm{Hz})$} & \multirow{2}{*}{ Overall (Linear) } \\
\hline 125 & 250 & 500 & 1000 & 2000 & 4000 & \\
\hline 69.3 & 68.3 & 59.1 & 57.9 & 45.7 & 44.7 & $72.2 \mathrm{~dB}$ \\
\hline
\end{tabular}

\begin{tabular}{|c|c|c|c|c|c|}
\hline \multicolumn{7}{|c|}{ A-WEIGHTED CORRECTION VALUE } \\
\hline \multicolumn{7}{|c|}{ FREQUENCY (Hz) } \\
\hline 125 & 250 & 500 & 1000 & 2000 & 4000 \\
\hline-16.1 & -8.6 & -3.2 & 0 & 1.2 & 1 \\
\hline
\end{tabular}

\begin{tabular}{|c|c|c|c|c|c|c|}
\hline \multicolumn{7}{|c|}{ A-WEIGHTED SOUND LEVEL (dBA) } \\
\cline { 1 - 5 } \\
\cline { 1 - 5 } & FREQUENCY (Hz) & \multirow{2}{*}{ Overall (Linear) } \\
\hline 53.2 & 59.7 & 55.9 & 57.9 & 46.9 & 45.7 & 63.5 dBA \\
\hline
\end{tabular}

Figure 14. Calculation data for sound transmission loss

Based on the noise data analysis, some options can be implemented on the gas turbine equipment for all three sections, including source, path, and receiver. For example, noise at the source can be reduced by using sound-absorbing material, such as sound foam inside the enclosure. Acoustic foam can be found easily on the market with various materials to absorb the noise. Some researchers study natural materials to be used for sound absorption. For example, Nasidi et al.'s (2021) study use sodium hydroxide concentration on coir fiber (coconut fiber) to increase sound absorption, significantly reducing the impact on medium frequency bands such as $1000 \mathrm{~Hz}$. As a comparison, Gas Turbines B and C show a high 
level of noise on the medium frequency band at the source. Other than that, gas turbine end-users can reduce the rotational tip speed of the rotor blades by controlling the gas turbine performance or reducing the fan pressure ratio that could significantly affect fan noise. In addition, the baseplate damper for the gas turbine can be modified to support the equipment during the operation. A survey was done by Krishna (1999) also recommends passive damping inside the turbine engine enclosure. Another study also states that installing an isolation pad between the turbine skid and the enclosure helps in reducing the noise transmission at the source (Lages, 1979).

Other than that, installing an acoustic panel on the gas turbine enclosure could reduce the noise along the path by ensuring the acoustic material used for the enclosure has a good efficiency in attenuating the noise level. Taking noise path reading from Gas Turbine $\mathrm{B}$ as an example, the noise comes from a connecting duct between gas turbine generator enclosures and its exhaust silencer. The noise path reading is significant around $250 \mathrm{~Hz}$ to $2000 \mathrm{~Hz}$, almost the same as the study done by Uddin et al. (2016). The previous research has modified the silencer, which can be applied to the Gas Turbine B noise path.

Another option could be relocating a gas turbine control panel at an acceptable distance. Depending on the location and area of work, noise at the receiver can be controlled by introducing an online parameter reader that can be monitored directly from a centralized control room (CCR) at the offshore facilities. Developing a program or software that can integrate the information from gas turbine panels can be helpful to operate and monitor the equipment remotely without having to collect the data on-site. Most of the time, industrial players focus on preparing a personal hearing protector for the workers who work near noisy equipment. However, previous research already concludes that hearing protectors used in the industry are only marginally associated with reduced odds of high-frequency hearing shifts, suggesting that hearing protectors provide inadequate noise reduction for many workers (Themann \& Masterson, 2019).

\section{CONCLUSION}

This study concludes that gas turbines produce a high volume of noise that could affect the hearing health of offshore workers. All three gas turbines from three different offshore facilities show that the noise level exceeds the noise exposure limit of $85 \mathrm{~dB}(\mathrm{~A})$. Based on the noise measurement, gas turbine users can take advantage of acoustic materials found in the market to reduce noise emissions at their facilities, such as modular acoustic panels that manage to reduce sound levels by up to $20 \mathrm{~dB}$ (A) based on calculation. The analysis shows that usage of acoustic material, such as modular panels, can attenuate the noise level for gas turbine equipment. It means that the high frequency of noise can be reduced by introducing proper materials, and noise measurement could test the effectiveness of the gas turbine noise control materials. Therefore, the objective of noise measurement study for gas turbine equipment at oil and gas facilities is accomplished. 


\section{ACKNOWLEDGEMENT}

This research is supported by Universiti Tun Hussein Onn (UTHM) through Tier 1 (vot H767).

\section{REFERENCES}

ASTM C423-17. (2017). Standard test method for sound absorption and sound absorption coefficients by the reverberation room method. ASTM International.

ASTM E90-09. (2009). Standard test method for laboratory measurement of airborne sound transmission loss of building partitions and elements. ASTM International.

CCOHS. (2019). Noise - Basic information. Canadian Centre for Occupational Health and Safety.

Cumpsty, N., \& Marble, F. (1977). Core noise from gas turbine exhausts. Journal of Sound and Vibration, 54(2), 297-309. https://doi.org/10.1016/0022-460X(77)90031-1

DOSH. (2019). Industry code of practice for management of occupational noise exposure and hearing conservation. Department of Occupational Safety and Health Malaysia.

El-Badawy, A., \& El-Arna'outy, W. (2007, July 9-12). Passive noise control of a burner-combustor system of a turbo-fan engine. In 14th International Congress of Sound and Vibration (pp. 1-8). Cairns, Australia. https://doi.org/10.13140/2.1.1065.5686

Hellberg, A., Andersson, T., \& Häggmark, A. (2012). Design, testing and performance of the recently developed 37 MW siemens SGT-750. In Turbo Expo: Power for Land, Sea, and Air (Vol. 44724, pp. 45-50). American Society of Mechanical Engineers. https://doi.org/10.1115/gt2012-68249

Krishna, C. R. (1999). Survey of noise suppression systems for engine generator sets. Brookhaven National Lab. https://doi.org/10.2172/752962

Lages, F. P. (1979). Air filtration and sound control systems for gas turbines-the start of the art. In Proceedings of the 8th Turbomachinery Symposium (pp. 83-94). Texas A\&M University Libraries. https://doi. org/10.21423/R1MX05

McAuliffe, D., Morlock, H., \& Oran, F. (1963). What to do about gas-turbine noise. In ASME 1963 Aviation and Space, Hydraulic, And Gas Turbine Conference and Products Show (Vol. 79924, p. V001T01A026). American Society of Mechanical Engineers. https://doi.org/10.1115/63-ahgt-77

Nasidi, I., Ismail, L., \& Samsudin, E. (2021). Effect of sodium hydroxide $(\mathrm{NaOH})$ treatment on coconut coir fibre and its effectiveness on enhancing sound absorption properties. Pertanika Journal of Science and Technology, 29(1), 693-706 https://doi.org/10.47836/pjst.29.1.37

Peters, R. J. (2013). Acoustics and noise control (3rd Ed.). Routledge. https://doi.org/10.4324/9781315847146

Sam, W. Y., Anita, A. R., Hayati, K. S., Haslinda, A., \& Lim, C. S. (2017). Prevalence of hearing loss and hearing impairment among small and medium enterprise workers in Selangor, Malaysia. Sains Malaysiana, 46(2), 267-274. http://dx.doi.org/10.17576/jsm-2017-4602-11 
Themann, C., \& Masterson, E. (2019). Occupational noise exposure: A review of its effects, epidemiology, and impact with recommendations for reducing its burden. The Journal of the Acoustical Society of America, 146(5), 3879-3905. https://doi.org/10.1121/1.5134465

Tiede, D. (1969). Measurement and control of gas turbine noise from an industrial vehicle. In ASME 1969 Gas Turbine Conference and Products Show (Vol. 79832, p. V001T01A025). American Society of Mechanical Engineers. https://doi.org/10.1115/69-gt-25

Uddin, M., Rahman, A., \& Sir, M. (2016). Reduce generators noise with better performance of a diesel generator set using modified absorption silencer. Global Journal of Research in Engineering, 16(1), 1-14. 
